\title{
Article
}

\section{Synthesis and catalytic performance of hierarchical MCM-22 zeolite aggregates with the assistance of carbon particles and fluoride ions}

\author{
Jianhua Yang*, Jun Chu, Jinqu Wang, Dehong Yin, Jinming Lu, Yan Zhang \\ State Key Laboratory of Fine Chemicals, Institute of Adsorption and Inorganic Membranes, School of Chemical Engineering, Dalian University of \\ Technology, Dalian 116024, Liaoning, China
}

\section{A R T I C L E I N F O}

\section{Article history:}

Received 28 June 2013

Accepted 4 September 2013

Published 20 January 2014

\section{Keywords:}

Methane dehydroaromatization

MCM-22 zeolite

Hierarchical pore

Fluoride route

Catalytic performance

\begin{abstract}
A B S T R A C T
Hierarchical MCM-22 zeolite aggregates (MCM-22-FC) were prepared by one-pot hydrothermal synthesis with the assistance of carbon particles and fluoride ions. The effects of carbon particles and fluoride ions on the morphology and catalytic properties of the MCM-22 zeolite were investigated. The hierarchical MCM-22-FC zeolite aggregates were constructed by intergrown and stacked thin MCM-22 lamellas and possessed macro-/mesopores and inherent micropores. The MCM-22-FC zeolite was modified to form the Mo/MCM-22-FC catalyst, which exhibited an improved benzene yield and aromatic selectivity as well as catalyst life in the methane dehydroaromatization (MDA) reaction. Based on $\mathrm{NH}_{3}$-TPD and pyridine-Fourier transform infrared spectroscopy measurements together with thermogravimetric analysis, we found that the improved MDA catalytic performance of Mo/MCM-22-FC resulted from the formation of more active $\mathrm{MoC}_{x}$ or $\mathrm{MoO}_{x} \mathrm{C}_{y}$ species that evolved from increased amounts of Brönsted acids with the assistance of fluoride ions. This promoted the diffusion of large molecule products because of the thin MCM-22 lamellas. Less excess Brönsted acid sites were retained in the Mo/HMCM-22-FC catalyst because the formation of active centers inhibited the formation of coke, which contributed to its improved aromatic selectivity.
\end{abstract}

(C) 2014, Dalian Institute of Chemical Physics, Chinese Academy of Sciences. Published by Elsevier B.V. All rights reserved.

\section{Introduction}

Over the past 30 years, the methane dehydroaromatization (MDA) reaction has attracted much attention as a promising route for the direct conversion of methane into high value-added chemicals [1-3]. To date, many important milestones in the development of Mo-based catalysts have been achieved, such as the bifunctional catalyst, an induction period, heavy carbonaceous deposits, and shape selective catalysis [4-7]. However, the direct conversion of $\mathrm{CH}_{4}$ under nonoxidative conditions is thermodynamically unfavorable; moreover, the deactivation of the catalyst with time-on-stream is very seriousness. These features restrict the industrial application of the
MDA reaction. Recently, MWW structure zeolites such as MCM-22 [8], MCM-49 [9], and MCM-56 [10] were shown to be effective MDA catalysts that have more favorable catalytic performance than other catalysts. Among the MWW zeolite catalysts, the Mo/HMCM-22 zeolite catalysts show particular competitive catalytic activity in the MDA reaction [11,12].

The major challenge of the MDA reaction is the high amount of carbonaceous deposits that cover the acid sites during the reaction, which leads to a decrease in the stability of the catalysts or the selectivity to benzene [13-15]. An increasing number of studies have focused on the origin of the carbonaceous deposits [16,17]. The carbonaceous deposits can be formed either on the acid sites or on the active Mo species of the zeolite

\footnotetext{
*Corresponding author. Tel: +86-411-84986147; Fax: +86-411-84986147; E-mail: yjianhua@dlut.edu.cn

This work was supported by the National Key Technology R\&D Program (2006BAE02B05), the National Natural Science Foundation of China (21076029), and the Program for New Century Excellent Talents in University (NCET-10-0286).

DOI: 10.1016/S1872-2067(12)60711-6 | http://www.sciencedirect.com/science/journal/18722067 | Chin. J. Catal., Vol. 35, No. 1, January 2014
} 
catalysts [17]. The Brönsted acid sites act as catalytic centers for aromatic products and also as sites for aromatic-type carbon deposition [18]. Successive chemical steps occur along the diffusion path within the zeolite crystallites, and condensation reactions are favorable, resulting in a fast coking rate [19].

Modifying the acidic properties and shape of the characteristic pore structure in the MCM-22 zeolite is effective in inhibiting carbonaceous deposits. The acidic properties of zeolite catalysts can be modified by the fluoride synthesis route. Fluoride ions have previously been proposed to act as mineralizing agents or as a promoter for the formation of $\mathrm{Si}-\mathrm{O}-\mathrm{Si}$ bonds [20-22]. By interacting with the zeolite skeleton, fluoride ions with high electronegativity change the electron density, the acid strength, and the acid quantity. Zeolites with a hierarchical pore structure, and that possess both micropores and mesopores are a new generation of zeolite catalyst. The introduction of mesopores to the microporous zeolite provides fast diffusion, overcoming the mass transport limitation, and resulting in improved catalytic activity $[23,24]$.

In this work, we explored a feasible method to combine a hierarchical structure and acidic modification in the MCM-22 zeolite catalyst to improve its catalytic performance in the MDA reaction. Hierarchical MCM-22 zeolite aggregate (MCM-22-FC) were synthesized from gel containing carbon particles and fluoride ions as a template and an acidic property modifier, respectively. The effect of carbon particles and fluoride ions on the morphology and properties of MCM-22 zeolite was examined. The MCM-22 zeolite was modified using ammonium molybdate $\left(\left(\mathrm{NH}_{4}\right)_{6} \mathrm{Mo}_{7} \mathrm{O}_{24} \cdot 4 \mathrm{H}_{2} \mathrm{O}\right)$ to form Mo/MCM-22 catalysts. Among the three investigated catalysts, the hierarchical Mo/MCM-22-FC catalyst showed improved aromatic selectivity and benzene yield and a long catalyst life in the MDA reaction. The structure-property relationship of the Mo-based MCM-22 catalysts in the MDA reaction was investigated by $\mathrm{N}_{2}$ adsorption, $\mathrm{NH}_{3}$ temperature-programmed desorption ( $\left.\mathrm{NH}_{3}-\mathrm{TPD}\right)$, pyridine adsorption infrared (Py-IR) spectroscopy, and thermogravimetric (TG) analysis.

\section{Experimental}

\subsection{Catalyst preparation}

Hierarchical MCM-22-FC zeolites with a Si/Al ratio of 15 were prepared by one-pot hydrothermal synthesis from a gel containing carbon particles and fluoride ions. Typically, a mixture containing $0.08 \mathrm{~g}$ sodium hydroxide $(96 \% \mathrm{NaOH}, \mathrm{Si}-$ nopharm Chemical Reagent Co, Ltd.), 0.53 g sodium metaaluminate $\left(\mathrm{NaAlO}_{2}\right.$, Tianjin Bodi Chemical Co, Ltd.), 0.81 g potassium fluoride $\left(\mathrm{KF} \cdot 2 \mathrm{H}_{2} \mathrm{O}\right.$, Tianjin Kemiou Chemical Reagent Co, Ltd.), $3.15 \mathrm{~g}$ carbon R400R (purchased from Cabot Corporation), 3.47 g HMI (> 98\%, Shanghai Longsheng Chemical Co, Ltd.), and $31.52 \mathrm{~g}$ deionized water was agitated at room temperature for $6 \mathrm{~h}$. A total of $10.52 \mathrm{~g}$ Ludox (AS-40, 40\% $\mathrm{SiO}_{2}$, Aldrich) was added to the mixture dropwise and vigorously stirred for $24 \mathrm{~h}$ to obtain a gel with a composition of $1.0 \mathrm{SiO}_{2}$ : $0.033 \mathrm{Al}_{2} \mathrm{O}_{3}: 0.06 \mathrm{Na}_{2} \mathrm{O}: 0.5 \mathrm{HMI}: 30 \mathrm{H}_{2} \mathrm{O}: 0.12 \mathrm{KF}$. The mass fraction of carbon R400R in the precursor solution was $10 \%$.
The final mixture was poured into a stainless-steel autoclave and then subjected to a crystallization reaction for $144 \mathrm{~h}$ at $438 \mathrm{~K}$ under agitation. After the crystallization, the samples were washed with deionized water and dried at $373 \mathrm{~K}$ overnight. The organic templates and carbon particles were eliminated by calcination at $823 \mathrm{~K}$ for $10 \mathrm{~h}$ at a heating and cooling rate of $1.8 \mathrm{~K} / \mathrm{min}$. A white MCM-22-FC material was obtained. For comparison, a conventional flaky MCM-22 was prepared by the same synthesis procedure from a gel but without the addition of fluoride ions and carbon particles, and the MCM-22-F and MCM-22-C zeolites were obtained from a gel with the addition of fluoride ions and carbon particles, respectively.

In our previous work, MCM-22 zeolite with high crystallinity $[11,25]$ was synthesized at the lower temperature of $423 \mathrm{~K}$ with $144 \mathrm{~h}$ for the crystallization reaction using the structure directing agent HMI from Aldrich. However, use of HMI from Shanghai Longsheng Chemical Corporation led to the formation of MCM-22 with much lower crystallinity and poor MDA catalytic performance (not shown here) under the same crystallization reaction conditions. The different purity and synthesis routes of the two HMIs are responsible for their different influence on the MCM-22 product.

The different $\mathrm{H}$-formed MCM-22 zeolite samples are denoted HMCM-22-FC, HMCM-22, HMCM-22-F, and HMCM-22-C and were obtained by successive exchange with $\mathrm{NH}_{4} \mathrm{NO}_{3}$ aqueous solution (1 mol/L) and calcination. Different Mo-based catalysts (6 wt\% Mo) denoted Mo/HMCM-22-FC, Mo/HMCM-22, Mo/HMCM-22-F, and Mo/HMCM-22-C were then prepared by impregnation with an aqueous solution of $\left(\mathrm{NH}_{4}\right)_{6} \mathrm{Mo}_{7} \mathrm{O}_{24} \cdot 4 \mathrm{H}_{2} \mathrm{O}$. After impregnation, the catalysts were dried at $373 \mathrm{~K}$ for $4 \mathrm{~h}$ and calcined in air at $823 \mathrm{~K}$ for $6 \mathrm{~h}$.

\subsection{Catalyst characterization}

X-ray powder diffraction (XRD) measurements were obtained on a Rigaku-Dmax 2400 X-ray diffractometer using $\mathrm{Cu}$ $K_{\alpha}$ radiation with a $2 \theta$ angle range from $5^{\circ}$ to $50^{\circ}$.

The morphology of the as-synthesized samples was observed by scanning electron microscopy (SEM) using a QUANTA-450 at an acceleration voltage of $20 \mathrm{kV}$. Transmission electron microscopy (TEM) measurement was carried out on a Tecnai F30 instrument, operating at $300 \mathrm{kV}$.

Nitrogen adsorption analyses were carried out with a Micromeritics ASAP-2020M adsorption analyzer at $77 \mathrm{~K}$. Before the adsorption measurements, the sample was degassed at 473 $\mathrm{K}$ for $6 \mathrm{~h}$. The surface area and pore size distribution were obtained by multipoint BET analysis and the BJH method, respectively.

The elements contained in the samples were detected by energy dispersive X-ray (EDX) measurements with a QUANTA450 instrument. The relative content of the elements was measured by the intensity of emitted characteristic X-rays of the sample elements.

The acidic properties of the samples were investigated by $\mathrm{NH}_{3}$-TPD and measured on a Quantachrome CHEMBET-3000 chemisorption analyzer. Py-IR spectra were collected using a Bruker TENSOR27 Fourier transform infrared spectrometer in 
the 4000-400 $\mathrm{cm}^{-1}$ range. For Py-IR measurements, all the samples were pressed into a self-supporting wafer. After the pre-treatment process, pyridine was adsorbed on the wafer for $5 \mathrm{~min}$ at room temperature. The bound species were sequentially desorbed at 423,573 , and $723 \mathrm{~K}$.

\subsection{Catalyst evaluation}

A certain quantity of Mo/HMCM-22-FC catalyst was evaluated continuously in a quartz tubular fixed-bed reactor for the MDA reaction. The reaction was carried out at $973 \mathrm{~K}$ under atmospheric pressure and a space velocity of $1500 \mathrm{ml} /(\mathrm{g} \cdot \mathrm{h})$. After adding helium gas by temperature programming and maintaining at $973 \mathrm{~K}$ for $1 \mathrm{~h}$, the feed gas mixture of $10 \% \mathrm{~N}_{2}$ and $90 \% \mathrm{CH}_{4}$ was changed. The products were analyzed online using a gas chromatograph equipped with double columns and with automatic sampling every $30 \mathrm{~min}$. A flame ionization detector was used for the analysis of organic components including $\mathrm{CH}_{4}, \mathrm{C}_{6} \mathrm{H}_{6}, \mathrm{C}_{7} \mathrm{H}_{8}$, and $\mathrm{C}_{10} \mathrm{H}_{8}$, and a thermal conductivity detector was used for the analysis of the components including $\mathrm{H}_{2}, \mathrm{~N}_{2}, \mathrm{CH}_{4}, \mathrm{CO}, \mathrm{C}_{2} \mathrm{H}_{4}$, and $\mathrm{C}_{2} \mathrm{H}_{6}$.

TG profiles were recorded on a Mettler-Toledo TG/ SDTA851e instrument. The rate of air flow was $60 \mathrm{ml} / \mathrm{min}$, and the catalysts were heated from 298 to $1073 \mathrm{~K}$ at a heating rate of $10 \mathrm{~K} / \mathrm{min}$.

\section{Results and discussion}

\subsection{Structural properties of the MCM-22 samples}

Four MCM-22 samples were synthesized and investigated in this work. XRD patterns of the conventional MCM-22, MCM-22-F, MCM-22-C, and MCM-22-FC zeolite samples are shown in Fig. 1. XRD patterns of MCM-22, MCM-22-F, and MCM-22-FC show characteristic MCM-22 structure peaks, and peakscharacteristic of other crystalline phases or amorphous phase are absent [26], confirming the formation of pure MCM-22 zeolite. The XRD patterns of the MCM-22-F and MCM-22-FC samples prepared from the gel in the presence of

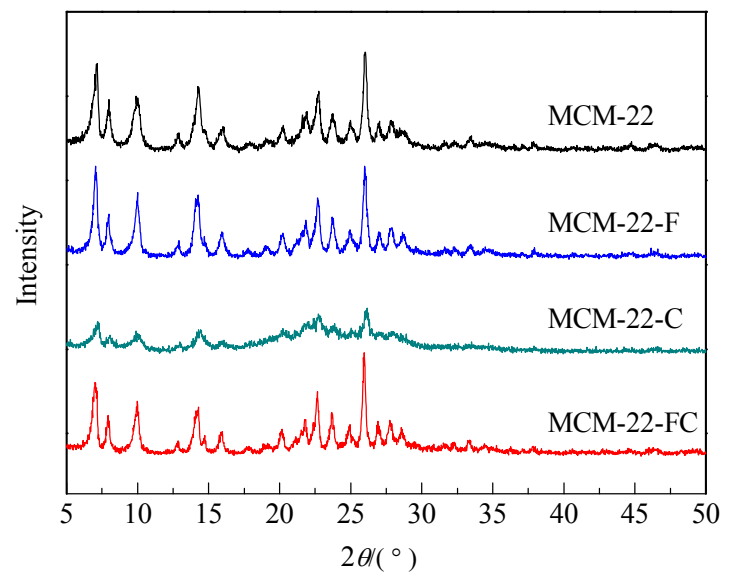

Fig. 1. XRD patterns of the four calcined MCM-22 zeolite samples synthesized with and without the assistance of carbon particles or/and fluoride ions. fluoride ions are slightly higher than those of MCM-22 without fluoride ions, suggesting that the fluoride ions can promote the growth of MCM-22 crystals, as expected. However, MCM-22-C showed low and wide characteristic MCM-22 peaks, indicating that MCM-22-C was partly retained in the MCM-22 crystal structure in addition to the presence of an amorphous phase.

The morphology and internal structure of the different MCM-22 zeolite samples were observed in more detail with SEM and TEM as shown in Fig. 2. The morphology of the MCM-22-FC zeolite synthesized with the addition of carbon particles in fluoride media differed significantly from that of the other sample. The MCM-22-FC zeolite's irregular micron-sized aggregates (Fig. 2(d)) were tightly constructed by many intergrown flaky crystals. Figure 2(e) further revealed that the intergrown and stacked structure was composed of smaller and thinner MCM-22 lamella building units. The thickness of one MCM-22 lamella was about $20 \mathrm{~nm}$. The high clear lattice fringes in Fig. 2(f) indicate highly crystalline thin flaky crystals in the building blocks.

Similarly, MCM-22-F showed micron-size aggregate morphology (Fig. 2(b)), but the flaky crystals of the building blocks were bigger, thicker and assembled more loosely than those in MCM-22-FC. In contrast, conventional MCM-22 zeolite (Fig. 2(a)) was a typical flaky crystal that was much thicker than those of MCM-22-F and MCM-22-FC. Consequently, the thin lamella units in MCM-22-FC might largely enhance its mass transfer and catalytic properties owing to the greatly reduced diffusion path compared to thick conventional flaky crystals.

However, MCM-22-C (Fig. 2(c)) is composed of many spherical particles that are distinct from the other three. This morphology of MCM-22-C is in accordance with the observed low
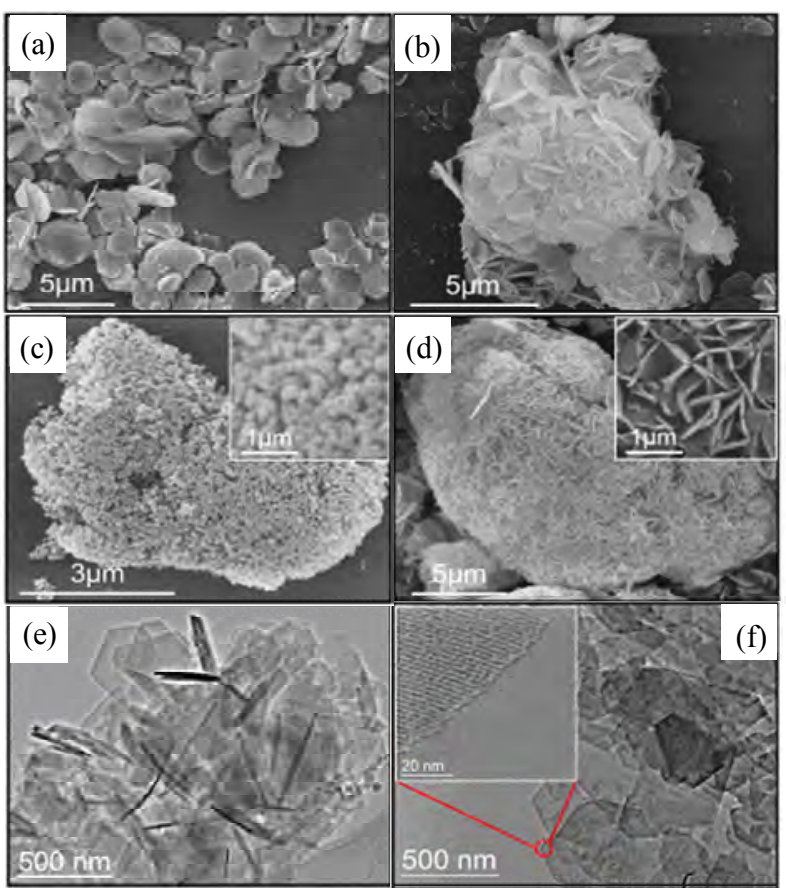

Fig. 2. SEM (a-d) and TEM (e, f) images of MCM-22 zeolite samples synthesized using the same synthesis procedures while varying the composition. (a) Conventional MCM-22; (b) MCM-22-F; (c) MCM-22-C; (d) MCM-22-FC; (e, f) TEM of MCM-22-FC zeolite. 
intensity XRD peaks of MCM-22-C as mentioned above. The Mo species modified Mo/HMCM-22-C catalyst gave a very poor benzene yield of less than $4 \%$ at $973 \mathrm{~K}$, and it had a very short catalytic life because of the low crystallinity of MCM-22. Therefore, Mo/HMCM-22-C catalyst will not be discussed further.

The difference in crystallinity and morphology between MCM-22 and MCM-22-FC suggests that the presence of carbon particles in the synthesis solution was not favorable for the growth of MCM-22 crystals. Perhaps the carbon particles that were dispersed in the synthesis solutions decreased the contact probability between the alumina and silica sources because of the hydrophobic surface nature of carbon. This favors the formation of massive crystal nuclei. Therefore, the crystal growth of MCM-22 is inhibited under a reduced nutrient contact probability and thus with limited nutrients. Fluoride ions can promote the formation of highly crystalline zeolites by controlling the relative rate of nucleation and crystal growth, as reported in the literature $[27,28]$. A synergistic action between carbon particles and fluoride ions contributed to the formation of MCM-22-FC constructed by many intergrown thin lamellas with a high degree of crystallinity.

$\mathrm{N}_{2}$ adsorption-desorption isotherms (Fig. 3(a)) of conventional MCM-22 and hierarchical MCM-22-FC aggregates show distinct hysteresis loops at a relative pressure $p / p_{0}$ in the range of $0.45-0.98$ and $0.75-0.98$, respectively. The hysteresis loop is caused by the capillary condensation of mesopores, indicating the presence of mesopores in the MCM-22 and MCM-22-FC zeolites. $\mathrm{N}_{2}$ adsorption-desorption isotherms of the MCM-22-FC aggregate show a sharp ascent at a relatively high pressure zone, indicating the presence of macropores, which is reasona-
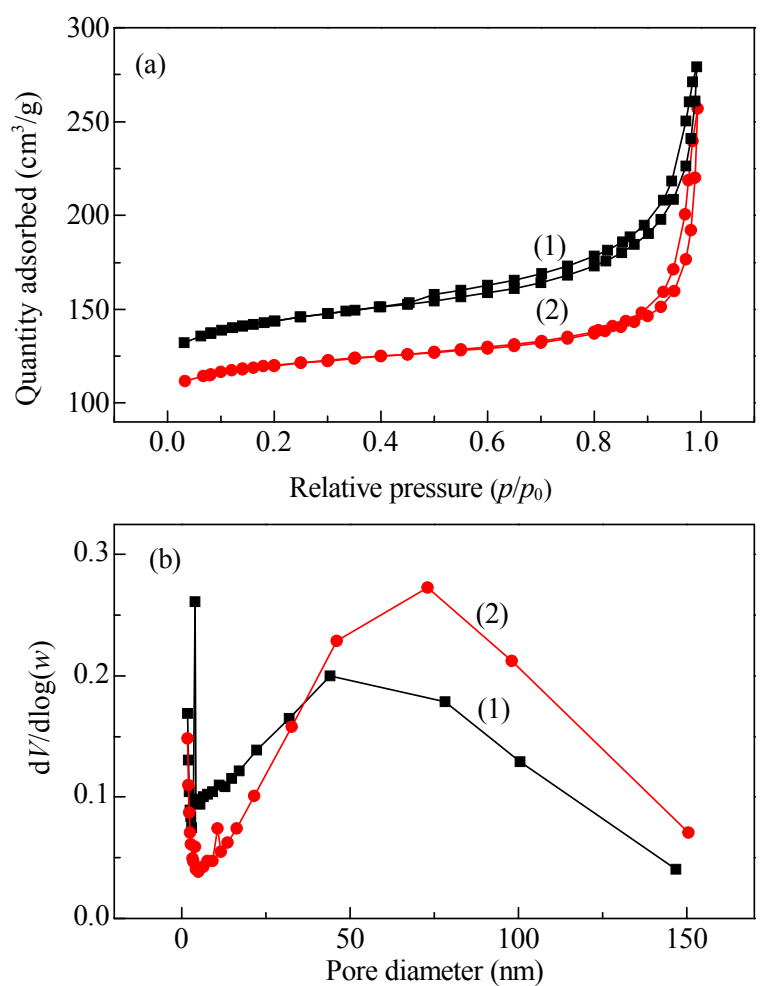

Fig. 3. $\mathrm{N}_{2}$ adsorption-desorption isotherms at $77 \mathrm{~K}$ (a) and pore size distribution (b) of the conventional MCM-22 (1) and MCM-22-FC (2) materials. bly attributable to the intercrystalline pores between the thin flaky crystals.

The hierarchical MCM-22-FC aggregate with thin flaky crystals show a wide pore size distribution model of the distinct macropores and mesopores with BJH diameters of 20-150 nm (Fig. 3(b)). Their pore size distributions indicate that the MCM-22-FC aggregate have larger pore size than the conventional MCM-22 zeolite. These phenomena indicate that the MCM-22-FC aggregate possess intrinsic micropores and mesopores as well as accessible macroporous channels, which further suggests the presence of hierarchical pore architecture.

EDX images of the calcined Mo/HMCM-22-FC catalyst along a target axis line of aggregates are shown in Fig. 4(b). These EDX images provide proof that fluoride ions are introduced into the MCM-22 zeolite catalysts. The mole ratio of $\mathrm{Si}$ to $\mathrm{Al}$ is nearly 12 (Fig. 4(c)), which is calculated from the different target axis lines. In addition, the detected carbon exists in the calcined Mo/HMCM-22-FC catalyst in the form of $\mathrm{CO}_{2}$ and uncalcined carbon particles.

\subsection{Acidic properties}

$\mathrm{NH}_{3}$-TPD profiles give information about acid strength distribution and amount of acid sites. Figure 5(a) shows $\mathrm{NH}_{3}-\mathrm{TPD}$ profiles of three HMCM-22 zeolites and their corresponding Mo/HMCM-22 catalysts. Three types of acid sites were simulated by Gauss curve fitting as shown in the simulation curves (Fig. 5(b)). Peaks from the different acid sites at specific desorption temperatures are shown. The $\mathrm{NH}_{3}$-TPD results of HMCM-22 in our work are reasonably consistent with that of MCM-22 with a Si/Al ratio of 12.5, as reported by Bao's group. [8].

As shown in Fig. 5(a), three desorption peaks centered at about 530, 580, and $720 \mathrm{~K}$ were observed for all the HMCM-22 samples, and these are attributed to peaks corresponding to weak acid sites, medium strength acid sites, and strong acid sites, respectively. For all the Mo/HMCM-22 catalysts, the peak areas of the strong acid sites decrease, and the peak areas of the medium strength acid sites increase. This proves that the

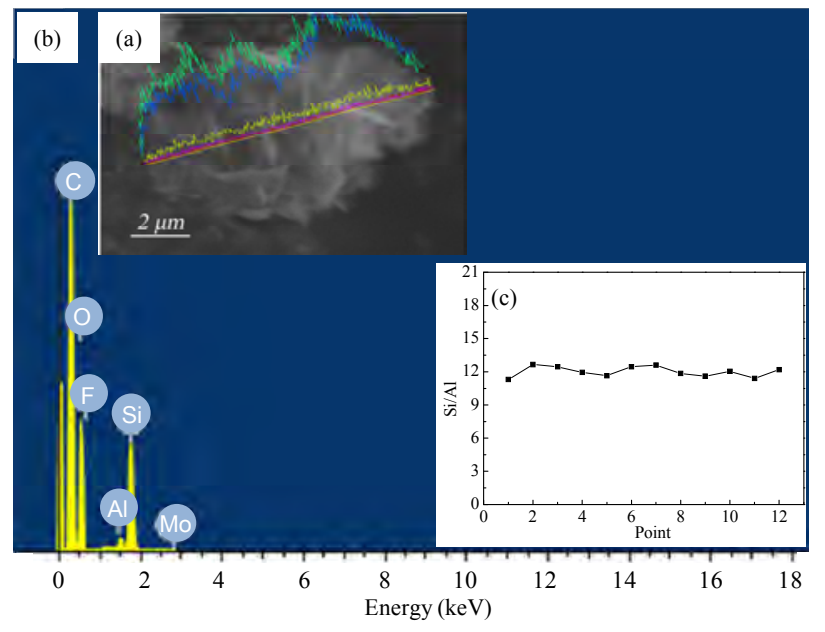

Fig. 4. SEM image (a) and EDX image (b) of the calcined Mo/HMCM-22-FC catalyst and the $\mathrm{Si} / \mathrm{Al}$ ratio (c) of the catalyst. 

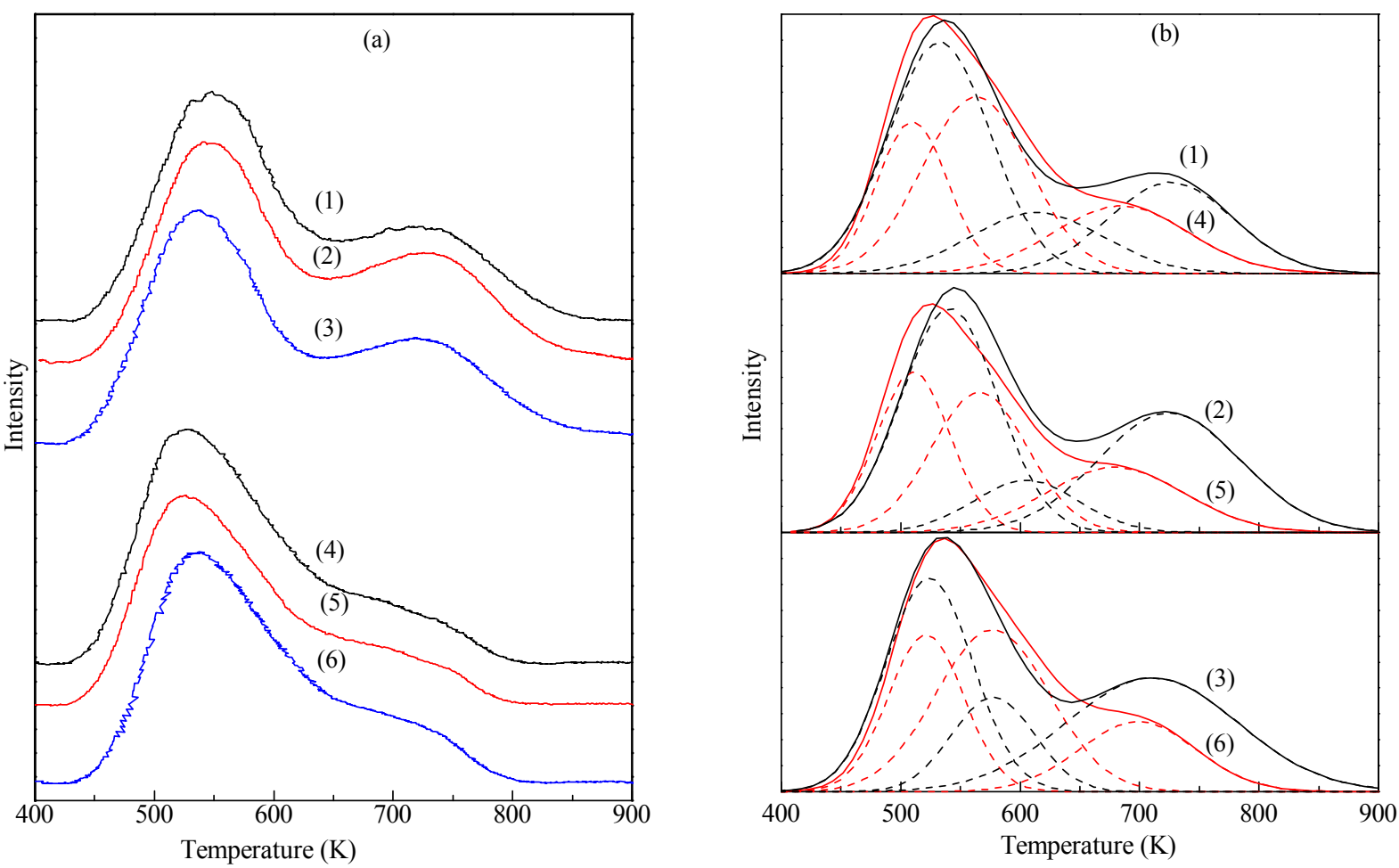

Fig. 5. $\mathrm{NH}_{3}$-TPD profiles (a) and simulation curves (b) of three HMCM-22 zeolites and their corresponding Mo/HMCM-22 catalysts. (1) HMCM-22; (2) HMCM-22-F; (3) HMCM-22-FC; (4) Mo/HMCM-22; (5) Mo/HMCM-22-F; (6) Mo/HMCM-22-FC.

impregnated Mo species strongly interact with strong acid sites and migrate within the zeolite channels to generate medium strong acid sites [29]. The acid strength of the three different types of acid sites weakened because of this strong interaction.

From the simulation curves of the $\mathrm{NH}_{3}$-TPD profiles, the acidic site distributions of the different catalysts were calculated and are summarized in Table 1 . Interestingly, the total amount of acid sites in the HMCM-22 zeolite or the Mo/HMCM-22 catalyst was $20 \%$ that of the total acid sites in the HZSM-5 and Mo/HZSM-5 catalysts [30]. The distinctly reduced amount of acid sites, particularly strong acid sites, might improve the stability of the catalyst in the MDA reaction.

It is worth noting that the HMCM-22-F and HMCM-22-FC zeolites with their fluoride ions contain more strong acid sites than the conventional zeolite. The acid sites act as powerful traps for the migration of molybdenum species within the zeolite channels [31]. Under the premise of a massive amount of strong acid sites in the HMCM-22-FC zeolite, the Mo/HMCM22-FC catalyst had the lowest amount of strong acid sites with a reduction of $55 \%$ after Mo species loading. This supports the deduction that more Mo species migrate into channels to form active species under an intense interaction with strong acid sites.

Py-IR spectra can qualitatively as well as quantitatively describe the Brönsted $\left(1540 \mathrm{~cm}^{-1}\right)$ and Lewis acid sites (1450 $\mathrm{cm}^{-1}$ ) and the acid strength of the acid centers in combination with the amount of acid sites, and these are obtained from the $\mathrm{NH}_{3}$-TPD profiles [32,33].

More specific spectrum information from the three catalysts Mo/HMCM-22, Mo/HMCM-22-F, and Mo/HMCM-22-FC at different desorption temperatures is shown in Fig. 6. For all three catalysts, the band at about $1540 \mathrm{~cm}^{-1}$, which is attributed to Brönsted acid sites, was observed and its intensity depends on the samples. Both the Mo/HMCM-22-F and Mo/HMCM-22-FC catalysts exhibit a high-intensity signal peak at this wavenumber, indicating the existence of massive pyridine complexes adsorbed on Brönsted acid sites, and this is related to the acidic $\equiv \mathrm{Si}-\mathrm{OH}-\mathrm{Al} \equiv$ groups. Another absorption band was observed among the pyridine bands that interact with Lewis acid sites at about $1450 \mathrm{~cm}^{-1}$, and this band is commonly assigned

Table 1

Acidic site distribution of three HMCM-22 zeolites and their corresponding Mo/HMCM-22 catalysts.

\begin{tabular}{|c|c|c|c|c|}
\hline \multirow{2}{*}{ Sample } & \multicolumn{4}{|c|}{ Amount of acid sites (mmol/g) } \\
\hline & Weak & Medium & Strong & Total \\
\hline HMCM-22 & $0.118(533 \mathrm{~K})$ & $0.042(614 \mathrm{~K})$ & $0.059(725 \mathrm{~K})$ & 0.219 \\
\hline Mo/HMCM-22 & $0.072(512 \mathrm{~K})$ & $0.078(570 \mathrm{~K})$ & $0.049(682 \mathrm{~K})$ & 0.199 \\
\hline HMCM-22-F & $0.089(536 \mathrm{~K})$ & $0.048(584 \mathrm{~K})$ & $0.088(723 \mathrm{~K})$ & 0.225 \\
\hline Mo/HMCM-22-F & $0.061(510 \mathrm{~K})$ & $0.068(566 \mathrm{~K})$ & $0.047(679 \mathrm{~K})$ & 0.176 \\
\hline HMCM-22-FC & $0.094(523 \mathrm{~K})$ & $0.041(577 \mathrm{~K})$ & $0.098(710 \mathrm{~K})$ & 0.236 \\
\hline Mo/HMCM-22-FC & $0.055(521 \mathrm{~K})$ & $0.093(576 \mathrm{~K})$ & $0.044(697 \mathrm{~K})$ & 0.192 \\
\hline
\end{tabular}




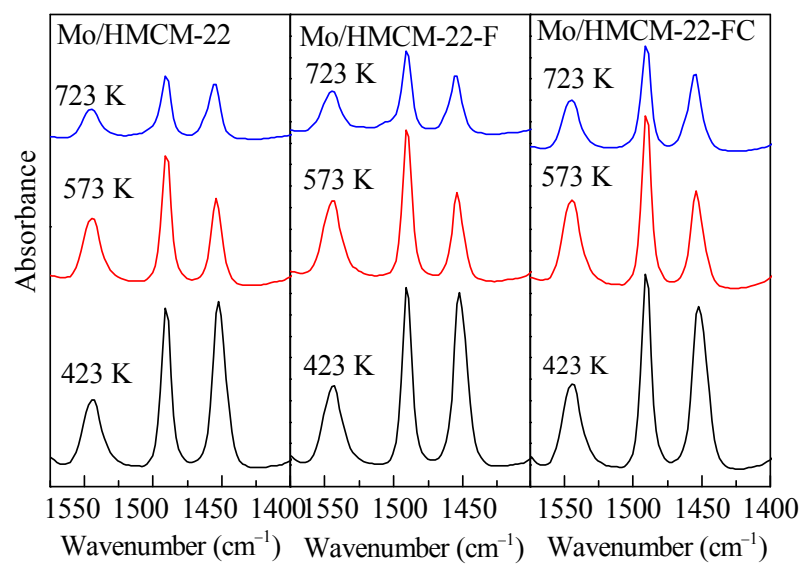

Fig. 6. Py-IR spectra of three Mo/HMCM-22 catalysts at different desorption temperatures.

to pyridine interacting with silanol groups [34].

As the desorption temperature increases, the interaction between pyridine and the Brönsted acid sites gradually reduces. It is obvious that the interaction between pyridine and the Brönsted acid sites in the Mo/HMCM-22-FC catalyst is stronger than that of the conventional Mo/HMCM-22 catalyst during the high-temperature desorption process. The amount of Brönsted acid sites, denoted $C_{\mathrm{B}}$, of the different Mo/HMCM-22 catalysts was quantitatively calculated and is listed in Table 2 . The integrated peak areas of the different acid sites are denoted $A_{\mathrm{B}}$ and $A_{\mathrm{L}}$, and these areas correlate with the distribution of the total amount of acid sites at specific desorption temperatures, as listed in Table 1.

The calculated amounts of Brönsted acid sites for the medium strong and strong acid sites located at 573 and $723 \mathrm{~K}$, respectively, are listed in Table 2 . The total amount of Brönsted acid sites decreased in the order Mo/HMCM-22-FC > Mo/HMCM-22-F > Mo/HMCM-22. The Mo/HMCM-22-FC catalyst possessed far more medium strength Brönsted acid sites $(0.051 \mathrm{mmol} / \mathrm{g})$ than the other two catalysts. The Mo/ HMCM-22-F and Mo/HMCM-22-FC catalysts possess almost the same amount of strong Brönsted acid sites. The origin and role of the medium strength and strong Brönsted acid sites in the catalytic performance during the MDA reaction will be discussed in detail later.

The Si/Al ratio of the three calcined catalysts was almost the same as shown by the $\mathrm{Si} / \mathrm{Al}$ ratio measured by XRF (X-ray fluorescence) and was 13.1, 12.0, and 12.3 for Mo/HMCM-22, Mo/HMCM-22-F, and Mo/HMCM-22-FC, respectively. This in-

Table 2

Brönsted acid site distribution for the three Mo/HMCM-22 catalysts at different desorption temperatures.

\begin{tabular}{lcccccc}
\hline \multirow{2}{*}{ Catalyst } & \multicolumn{2}{c}{$A_{\mathrm{B}} /\left(A_{\mathrm{B}}+A_{\mathrm{L}}\right)$} & & \multicolumn{3}{c}{$C_{\mathrm{B}} /(\mathrm{mmol} / \mathrm{g})$} \\
\cline { 2 - 3 } \cline { 5 - 7 } & $573 \mathrm{~K}$ & $723 \mathrm{~K}$ & & $573 \mathrm{~K}$ & $723 \mathrm{~K}$ & Total \\
\hline Mo/HMCM-22 & 0.52 & 0.37 & & 0.041 & 0.018 & 0.059 \\
Mo/HMCM-22-F & 0.57 & 0.49 & & 0.039 & 0.023 & 0.062 \\
Mo/HMCM-22-FC & 0.55 & 0.48 & & 0.051 & 0.022 & 0.073 \\
\hline
\end{tabular}

$A_{\mathrm{B}}$ : Peak area attributed to Brönsted acid sites in the Py-IR spectra. $A_{\mathrm{L}}$ : Peak area attributed to Lewis acid sites in the Py-IR spectra. $C_{\mathrm{B}}$ : Molar concentration of Brönsted acid sites per gram of the catalyst. dicates that the higher acid strength and the amount of Brönsted acid sites for Mo/HMCM-22-FC and Mo/MCM-22-F did not come from the $\mathrm{Al}$ content but from the incorporation of fluoride into the MCM-22 framework. It has been reported that fluoride ions are incorporated into zeolite frameworks upon synthesis in a fluoride medium or by post-synthesis modification mainly in the form of penta-coordinated $\left[\mathrm{SiO}_{4 / 2} \mathrm{~F}\right]^{-}$units, or sometimes in the form of tetrahedrally coordinated $\left[\mathrm{SiO}_{3 / 2} \mathrm{~F}\right]$ units [35-37]. For MCM-22-FC, KF as a source of fluoride was found to be favorable for the formation of $\left[\mathrm{SiO}_{3 / 2} \mathrm{~F}\right]-$ units [38]. $\mathrm{F}$ atoms in tetrahedral $\left[\mathrm{SiO}_{3 / 2} \mathrm{~F}\right]^{-}$accept electronic density from neighboring Si because of the electron inductive effect, which enhances the ionization of the proton and reinforces the acidity and amount of acid sites in terms of Brönsted acid sites. Therefore, it is reasonable to speculate that the aforementioned increased amount of Brönsted acid sites in MCM-22-FC comes from the formation of $\left[\mathrm{SiO}_{3 / 2} \mathrm{~F}\right]^{-}$units. These findings again demonstrate that the acidic properties of zeolites can be modified by the fluoride synthesis route.

\subsection{Catalyst performance evaluation}

A Mo content (mass fraction) of $6 \%$ was chosen for all three Mo/HMCM-22, Mo/HMCM-22-F, and Mo/HMCM-22-FC catalysts, and this has been reported to be the optimum content for Mo/HMCM-22 [29]. To compare the catalytic performance of these three catalysts, the catalysts were prepared using the same procedure and were evaluated in the MDA reaction under the same reaction conditions. The results are shown in Fig. 7.

Although the three catalysts exhibit similar $\mathrm{CH}_{4}$ conversion, Mo/HMCM-22-FC gave the highest target benzene yield. The highest benzene yield was $7.7 \%$ and remained above $6 \%$ even after 52 h. Compared with Mo/HMCM-22, the benzene yield was about $2 \%$ higher and increased by $25 \%$. Notably, the yield of carbonaceous deposits in Mo/HMCM-22-FC was the lowest at about $3.5 \%$, and this is a decrease of nearly $50 \%$ by comparison with Mo/HMCM-22. Therefore, the Mo/HMCM-22-FC catalyst gave the highest benzene yield and aromatic selectivity because of the low carbonaceous deposits on the active centers.

\subsection{Structure-property relationship of Mo/HMCM-22 catalysts for the MDA reaction}

It is important to understand the structure-property relationship of the three obtained catalysts for the MDA reaction. The MDA reaction path on the Mo-based catalysts is complicated. It has been recognized that the $\mathrm{MoO}_{3}$ species can migrate into zeolite channels via the gas phase or by surface diffusion, and it can then react with Brönsted acid sites to form $\left(\mathrm{MoO}_{2}(\mathrm{OH})\right)^{+}$during the calcination of Mo/HMCM-22 and during the induction period of the MDA reaction. $\left(\mathrm{MoO}_{2}(\mathrm{OH})\right)^{+}$can form $\left(\mathrm{Mo}_{2} \mathrm{O}_{5}\right)^{2+}$, which can be further reduced by $\mathrm{CH}_{4}$ to form $\mathrm{MoC}_{x}$ and $\mathrm{MoO}_{x} \mathrm{C}_{y}$ as active centers during the induction period $[39,40]$. $\left(\mathrm{MoO}_{2}(\mathrm{OH})\right)^{+}$has been suggested to give medium strong Brönsted acid site [29,31]. For the Mo/MCM-22-FC catalyst, the aforementioned medium strong Brönsted acid sites listed in Table 2, which can be attributed to $\left(\mathrm{MoO}_{2}(\mathrm{OH})\right)^{+}$, 

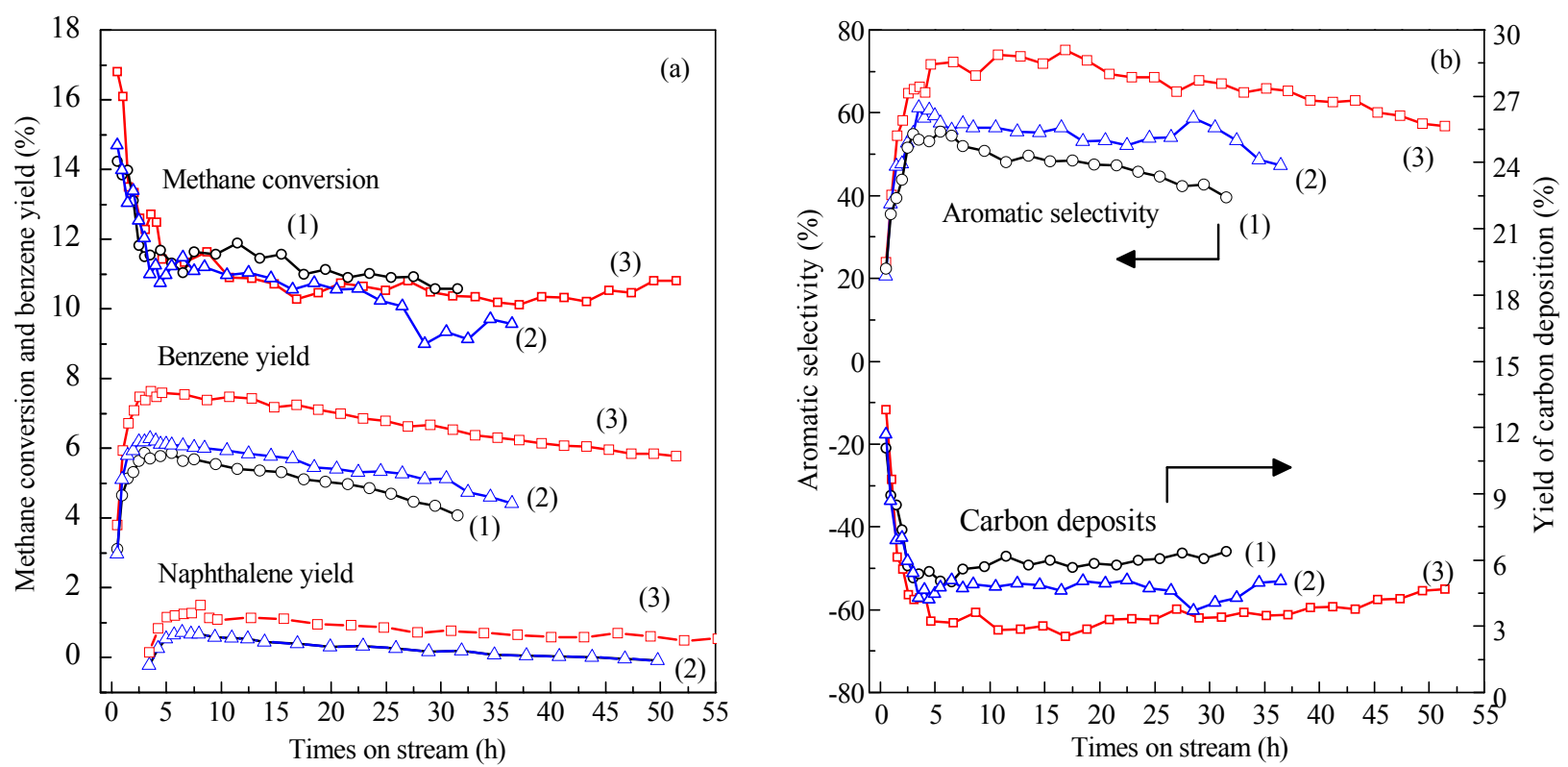

Fig. 7. Catalytic performance of three Mo/HMCM-22 catalysts measured during the MDA reaction. (a) Methane conversion, benzene yield, and naphthalene yield; (b) Aromatic selectivity and carbon deposits. (1) Mo/HMCM-22; (2) Mo/HMCM-22-F; (3) Mo/HMCM-22-FC.

evolve naturally into more active centers of $\mathrm{MoC}_{x}$ or $\mathrm{MoO}_{x} \mathrm{C}_{y}$. This consideration is further supported by the observed highest $\mathrm{CH}_{4}$ conversion of $17 \%$ during the induction period of the MDA reaction (Fig. 7(a)).

The pore size and structure of the zeolites are also crucial for catalytic activity and the distribution of products because of mass diffusion [19]. In our case, the thickness of the MCM-22 crystal lamella units decreases in the order MCM-22 > MCM-22-F > MCM-22-FC, as mentioned above. The thin MCM-22 crystal lamella in the MCM-22-FC crystals shortens the diffusion path, and this facilitates the transfer of large molecule products such as benzene from outside the zeolite channels. Furthermore, the presence of macropores and mesopores in the hierarchical Mo/HMCM-22-FC catalyst enables an easier transfer of large molecule products and facilitates the accessibility of active centers, which reduces the possibility of coke formation, especially aromatic-type carbonaceous deposits on the Brönsted acid sites. Therefore, Mo/HMCM-22-FC gave the lowest yield of carbonaceous deposits, whereas Mo/HMCM-22 gave the highest yield of carbonaceous deposits.

It is also accepted that excess Brönsted acid sites result in catalyst deactivation because Brönsted acid sites are responsible for the formation of aromatic products and also for the deposition of aromatic-type coke causing catalyst deactivation $[16,17,41]$. TG information for the spent catalysts is shown in Fig. 8 and Table 3. From Fig. 8, the Mo/HMCM-22-F sample gave the least coke. As shown in Table 3, the Mo/HMCM-22-F sample gave the least coke at high temperature (ca. 850-870 K, peak $\mathrm{H}$ ), and this was associated with Brönsted acid sites, indicating that the number of retained Brönsted acid sites in the catalyst was the lowest. The lower amount of coke formed at low temperature (ca. $770-790 \mathrm{~K}$, peak $\mathrm{L}$ ) in the Mo/HMCM-22-FC catalyst supports the lower coke covering on $\mathrm{MoC}_{x}$ and $\mathrm{MoO}_{x} \mathrm{C}_{y}$ [18]. The reason is probably a fast mass transfer from the aforementioned thin MCM-22 flaky crystals. The lowest amount of excess Brönsted acid sites and the formation of more $\mathrm{MoC}_{x}$ or $\mathrm{MoO}_{x} \mathrm{C}_{y}$ can lead to the highest aromatic selectivity and an enhanced catalyst life of the Mo/HMCM-22-FC catalyst.

In summary, the high benzene yield and selectivity as well as the long catalyst life comes from the hierarchical pore structure and the thin MCM-22 lamella building blocks of Mo/HMCM-22-FC aggregate catalysts. The structure can func-

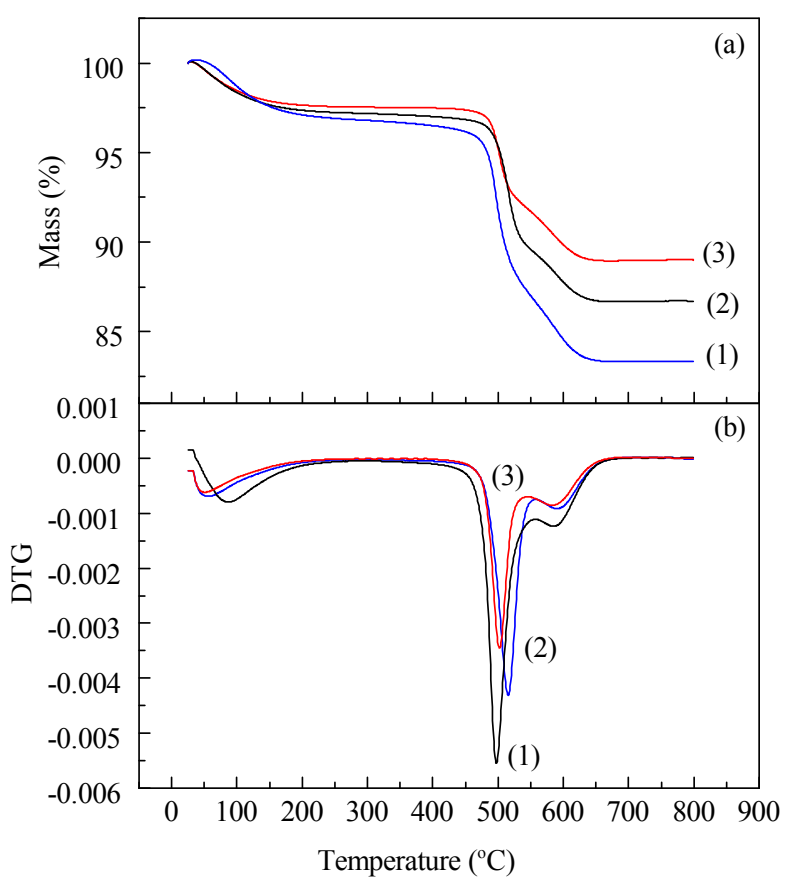

Fig. 8. TG (a) and DTG (b) curves of the coked Mo/HMCM-22 (1), Mo/HMCM-22-FC (2), and Mo/HMCM-22-F (3) catalysts after being subjected to the MDA reaction for 32,37 , and $52 \mathrm{~h}$, respectively. 
Table 3

The amount of carbonaceous deposits on the coked catalysts after being subjected to the MDA reaction for 32,37 , and $52 \mathrm{~h}$, respectively.

\begin{tabular}{|c|c|c|c|c|c|c|c|}
\hline \multirow{2}{*}{ Catalyst } & \multicolumn{2}{|c|}{ Peak temperature $(\mathrm{K})$} & \multicolumn{2}{|c|}{ Peak area } & \multicolumn{3}{|c|}{ Coke amount $(\mathrm{mg} /(\mathrm{h} \cdot \mathrm{g}))$} \\
\hline & Peak L & Peak H & Peak L & Peak H & Peak L & Peak H & Total \\
\hline Mo/HMCM-22 & 772 & 851 & 0.23 & 0.18 & 2.91 & 2.28 & 5.19 \\
\hline Mo/HMCM-22-F & 775 & 855 & 0.13 & 0.11 & 1.61 & 1.36 & 2.97 \\
\hline Mo/HMCM-22-FC & 787 & 868 & 0.21 & 0.09 & 1.79 & 0.77 & 2.56 \\
\hline
\end{tabular}

tionally promote the diffusion of large molecule products and facilitate the accessibility of active centers. Furthermore, with acidic modification in fluoride media, Mo/HMCM-22-FC catalyst contain more Brönsted acid sites and evolved more Mo species to form more active centers. The formation of many active centers and few excess Brönsted acid sites lowers the amount of uncontrollable carbonaceous deposits. Consequently, the hierarchical structure with many active centers in the Mo/HMCM-22-FC catalyst is important for excellent catalytic performance and controllable carbonaceous deposits in the MDA reaction.

\section{Conclusions}

Hierarchical MCM-22-FC aggregate synthesized with the right amount of carbon particles in a fluoride medium were prepared by in situ hydrothermal synthesis. The Mo/HMCM-22-FC catalyst exhibited improved catalytic performance for in the MDA reaction in terms of aromatic selectivity and catalyst life. Upon the addition of fluoride ions, the acidic strength and amount of Brönsted acid sites in the Mo/HMCM-22-FC catalyst were reinforced in favor of the formation of more active centers. The MCM-22-FC aggregate were constructed by many thin lamellas with high crystallinity, and they possessed a hierarchical pore structure, which contributed to a reduction in carbonaceous deposits and an enhanced aromatic selectivity by improving the mass transport of large molecule products. The few Brönsted acid sites that remained in the catalyst after the formation of many catalytic active species because of the Mo species inhibited the formation of coke and improved the aromatic selectivity and catalyst life. This demonstrated that the modification of both the pore structure and acidic properties of the Mo-based catalysts is important for improved catalytic performance and controllable carbonaceous deposits in the MDA reaction.

\section{References}

[1] Wang L S, Tao L X, Xie M S, Xu G F, Huang J S, Xu Y D. Catal Lett, 1993, 21: 35

[2] Marczewski M, Marczewska H, Debowiak M. React Kinet Catal Lett, 1995, 55: 207

[3] Cui Y B, Xu Y B, Lu J Y, Suzuki Y, Zhang Z G. Appl Catal A, 2011, 393: 348

[4] Matus E V, Ismagilov I Z, Sukhova O B, Zaikovskii V I, Tsikoza L T, Ismagilov Z R, Moulijn J A. Ind Eng Chem Res, 2006, 46: 4063

[5] Ma D, Shu Y Y, Cheng M J, Xu Y D, Bao X H. J Catal, 2000, 194: 105

[6] Liu B S, Jiang L, Sun H, Au C T. Appl Surf Sci, 2007, 253: 5092

[7] Bai J, Liu S L, Xie S J, Xu L Y, Lin L U. Catal Lett, 2003, 90: 123

[8] Liu L, Ma D, Chen H Y, Zhang H, Cheng M J, Xu Y D, Bao X H. Catal Lett, 2006, 108: 25
[9] Sun C Y, Yao S D, Shen W J, Lin L W. Microporous Mesoporous Mater, 2009, 122: 48

[10] Xing H J, Zhang Y, Jia M J, Wu S J, Wang H S, Guan J Q, Xu L, Wu T H, Kan Q B. Catal Commun, 2008, 9: 234

[11] Chu N B, Yang J H, Wang J Q, Yu S X, Lu J M, Zhang Y, Yin D H. Catal Commun, 2010, 11: 513

[12] Gu L J, Ma D, Hu G, Wu J J, Wang H X, Sun C Y, Yao S D, Shen W J, Bao X H. Dalton Trans, 2010, 39: 9705

[13] Wang H X, Su L L, Zhuang J G, Tan D L, Xu Y D, Bao X H.J Phys Chem $B, 2003,107: 12964$

[14] Liu H M, Su L L, Wang H X, Shen W J, Bao X H, Xu Y D. Appl Catal A, 2002, 236: 263

[15] Xu Y D, Bao X H, Lin L W. J Catal, 2003, 216: 386

[16] Ma D, Wang D Z, Su L L, Shu Y Y, Xu Y D, Bao X H. J Catal, 2002, 208: 260

[17] Liu H M, Li T, Tian B L, Xu Y D. Appl Catal A, 2001, 213: 103.

[18] Liu H W, Shen W J, Bao X H, Xu Y D. Appl Catal A, 2005, 295: 79

[19] Bergeudd H, Jonsson M, Ngström D, Malmström E. J Mol Catal A, 2009, 305: 69

[20] Xu M C, Wang W, Seiler M, Buchholz A, Hunger M. J Phys Chem B, 2002, 106: 3202

[21] Shayib R M, George N C, Seshadri R, Burton A W, Zones S I, Chmelka B F. J Am Chem Soc, 2011, 133: 18728

[22] Liu X L, Ravon U, Tuel A. Chem Mater, 2011, 23: 5052

[23] Meng X J, Nawaz F, Xiao F S. Nano Today, 2009, 4: 292

[24] Zhou J, Hua Z L, Liu Z C, Wu W, Zhu Y, Shi J L. ACS Catal, 2011, 1: 287

[25] Chu N B, Wang J Q, Zhang Y, Yang J H, Lu J M, Yin D H. Chem Mater, 2010, 22: 2757

[26] Corma A, Corell C, Pérez-Pariente J. Zeolites, 1995, 15: 2

[27] Lindner T, Lechert H. Zeolites, 1994, 14: 582

[28] Villaescusa L A, Wheatley P S, Bull I, Lightfoot P, Morris R E. J Am Chem Soc, 2001, 123: 8797

[29] Shu Y Y, Ma D, Xu L Y, Xu Y D, Bao X H. Catal Lett, 2000, 70: 67

[30] Ren D M, Wang X S, Li G, Cheng X J, Long H Y, Chen L D. J Nat Gas Chem, 2010, 19: 646

[31] Ma D, Zhang W P, Shu Y Y, Liu X M, Xu Y D, Bao X H. Catal Lett, 2000, 66: 155

[32] Zheng S R, Heydenrych H R, Jentys A, Lercher J A.J Phys Chem B, 2002, 106: 9552

[33] Musilová-Pavlačková Z, Zones S I, Čejka J. Top Catal, 2010, 53: 273

[34] Serrano D P, Garcia R A, Vicente G, Linares M, Prochazkova D, Cejka J. J Catal, 2011, 279: 366

[35] Youngman R E, Sen S.J Non-Cryst Solids, 2004, 349: 10

[36] Louis B, Kiwi-Minsker L. Microporous Mesoporous Mater, 2004, 74: 171

[37] Goa Y, Wu P, Tatsumi T. J Phys Chem B, 2004, 108: 4242

[38] Fang X Q, Wang Q, Zheng A M, Liu Y M, Wang Y N, Deng X J, Wu H H, Deng F, He M Y, Wu P. Catal Sci Technol, 2012, 2: 2433

[39] Borry R WIII, Kim Y H, Huffsmith A, Reimer J A, Iglesia E. J Phys Chem B, 1999, 103: 5787

[40] Li W, Meitzner G D, Borry R W III, Iglesia E. J Catal, 2000, 191: 373

[41] Ma D, Lu Y, Su L L, Xu Z S, Tian Z J, Xu Y D, Lin L W, Bao X H.J Phys Chem B, 2002, 106: 8524 


\title{
Graphical Abstract
}

Chin. J. Catal., 2014, 35: 49-57 doi: 10.1016/S1872-2067(12)60711-6

Synthesis and catalytic performance of hierarchical MCM-22 zeolite aggregates with the assistance of carbon particles and fluoride ions

Jianhua Yang*, Jun Chu, Jinqu Wang, Dehong Yin, Jinming Lu, Yan Zhang Dalian University of Technology

Hierarchical MCM-22 zeolite aggregates constructed by intergrown and stacked thin MCM-22 lamellas were prepared by one-pot hydrothermal synthesis with the assistance of carbon particles and fluoride ions. The Mo/MCM-22-FC catalyst exhibited an improved benzene yield and aromatic selectivity as well as catalyst life in the methane dehydroaromatization reaction.

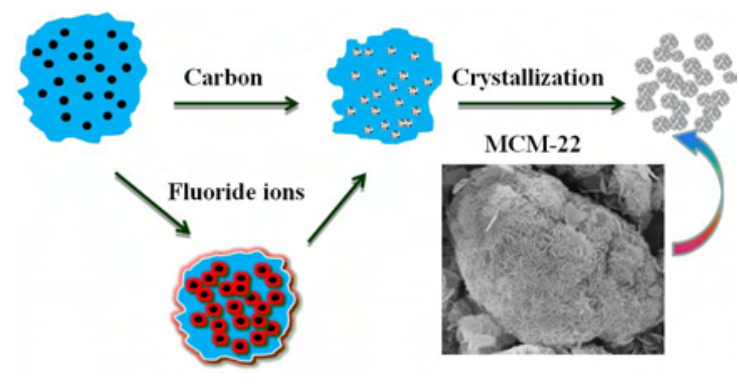

\section{炭黑颗粒及氟粒子辅助法合成多级结构MCM-22分子篮及其催化性能}

\author{
杨建华 ${ }^{*}$, 初 筠, 王金渠, 殷德宏, 鲁金明, 张 艳 \\ 大连理工大学精细化工国家重点实验室, 吸附与无机膜研究所, 辽宁大连 116024
}

摘要: 以碳黑为第二模板剂在氟离子体系中一步水热合成了多级结构MCM-22分子笁组装体(简称为MCM-22-FC). 考察了碳黑 和氟离子对MCM-22分子篮形貌和催化性能的影响. MCM-22-FC分子篮是由大量片状晶体交错生长形成的组装体结构, 其中 MCM-22 的片层结构更薄, 在其固有的微孔中存在的晶间孔呈现大孔和介孔的特征. MCM-22-FC 负载Mo后得到的 Mo/MCM-22-FC催化剂在甲烷无氧芳构化反应(MDA)中提高了苯收率和芳烃选择性, 并且提高了催化剂的寿命. 通过氨气程序 升温脱附 $\left.\mathrm{NH}_{3}-\mathrm{TPD}\right)$ 表征, 吡啶红外(Py-IR)表征, 结合热重(TG)分析, 得出的结论是Mo/MCM-22-FC在MDA中优越的催化性能是 由于氟离子进入到分子篮骨架当中, 形成具有拉电子效应的结构单元, 从而提高了分子篮的Brönsted酸量, 较多的Brönsted酸性位 将更多的 $\mathrm{Mo}$ 物种迁移至分子笁孔道内部, 形成更多的 $\mathrm{MoC}_{x}$ 或 $\mathrm{MoO}_{x} \mathrm{C}_{y}$ 活性物种以及更有利于大分子产物扩散的 $\mathrm{MCM}-22$ 薄片层 的结构. 少量过剩的Brönsted酸性位在成型后保留在Mo/HMCM-22-FC催化剂活性中心抑制了积碳的形成, 也有助于改善芳烃的 选择性.

关键词：甲烷芳构化；MCM-22分子笁；多级孔道；氟路线；催化性能

收稿日期: 2013-06-28. 接受日期: 2013-09-04. 出版日期: 2014-01-20.

*通讯联系人. 电话: (0411)84986147; 传真: (0411)84986147; 电子信箱: yjianhua@dlut.edu.cn

基金来源：国家科技支撑计划(2006BAE02B05); 国家自然科学基金(21076029); 新世纪优秀人才支持计划(NCET-10-0286).

本文的英文电子版由Elsevier出版社在ScienceDirect上出版(http://www.sciencedirect.com/science/journal/18722067). 